\title{
Simultaneous electrochemical determination of epinephrine and acetylcholine using modified screen printed electrode
}

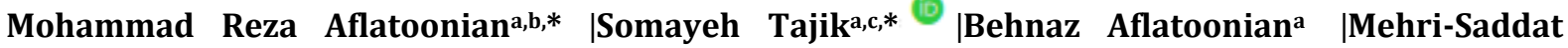 \\ Ekrami-Kakhkid |Reza Alizadehe
}

${ }^{a}$ Neuroscience Research Center, Kerman University of Medical Sciences, Kerman, Iran

${ }^{b}$ Leishmaniasis Research Center, Kerman University of Medical Sciences, Kerman, Iran

cResearch Center for Tropical and Infectious Diseases, Kerman University of Medical Sciences, Kerman, Iran

${ }^{d}$ Esfarayen University of Technology, Esfarayen, Iran

eDepartment of Chemistry, Faculty of Science, Qom University, Qom, Iran

*Corresponding Authors:

Mohammad Reza Aflatoonian, Somayeh

Tajik

Email: m.aflatoonian97@gmail.com,

Tajik_s1365@yahoo.com

Tel.: +98 (34) 32112794

Electrochemical behaviors of epinephrine and acetylcholine were investigated, using cyclic voltammetry, on the Ag- ZnO modified screen-printed electrode (Ag-ZnO/SPE). Ag-ZnO nanoplates showed excellent electrocatalytic activity toward the oxidation of epinephrine and acetylcholine compared with bare SPE in 0.1 M PBS. Under the optimized experimental conditions, a linear response obtained in the range of 0.13 to $450.00 \mu \mathrm{M}$ with detection limit of $0.04 \mu \mathrm{M}$ for epinephrine. Ag$\mathrm{ZnO} / \mathrm{SPE}$ exhibits good stability, reproducibility and repeatability, and the method has been successfully applied for detection of epinephrine and acetylcholine in their pharmaceutical and biological samples with satisfactory recovery.

\section{KEYWORDS}

Epinephrine; acetylcholine; Ag-ZnO nanoplates; screen printed electrode.

\section{Introduction}

Epinephrine [1-(3,4-dihydroxyphenyl)-2methyloaminoethanol], often called adrenaline, is one of the most important and well-known catecholamine neurotransmitters in mammalian central nervous systems, which plays an important role in the function of the central nervous, hormonal and cardiovascular systems [1,2]. Many life phenomena are connected to the concentration of epinephrine in blood. Changes of its concentration in blood show the way to many diseases. Low levels of epinephrine have been found in patients with Parkinson's disease and presence of epinephrine in the body affects the regulation of blood pressure and the heart rate, lipolysis, immune system, and glycogen metabolism. Medically, epinephrine has been used as a common emergency healthcare medicine [3].
Acetylcholine (ACh), an organic chemical, is released by nerve cells to deliver signals to the other cell types and acts as a neurotransmitter. Acetylcholine functions as anAcetylcholine functions as a neuromodulator in the peripheral nervous system (PNS) and central nervous system (CNS). In the PNS, acetylcholine binds to acetylcholine receptors (AChR) and regulates muscle contraction where as in the CNS, it plays a crucial role in the processes related to behavioral activities, arousal, attention, learning and memory. Synthesis of acetylcholine takes place in nerve terminals from acetyl coenzyme A and choline. This reaction is catalysed by choline acetyltransferase. The acetylcholine concentration in a healthy human blood is approximately $8.66 \pm 1.02 \mathrm{nM}$ [4].

Decreases in the level of acetylcholine cause various neurological disorders, 
including Parkinson's disease, Alzheimer's and dementia, and schizophrenia. On the other hand, increases in the level of acetylcholine result in a decreased heart rate and increased production of saliva [5].

Acetylcholine and epinephrine also alter the cardiac function by changing the ion fluxes and electric potential disturbances across cell membranes. Hence, the simultaneous determination of acetylcholine and epinephrine is very important in biological sciences and clinical analysis.

The creation of even smaller, more robust and selective devices for the chemical determination of acetylcholine, epinephrine, and other species is one of the great challenges of current analytical chemistry. Recently, electrochemical sensors have gained widespread acceptance for monitoring many substances. The main advantages of electrochemical methods over other detection methods are their high sensitivity, selectivity, instrument portability, low cost, miniaturization and fast response times [614].

Screen printing technology has been evolved for designing feasible disposable chemical sensors, which is involved in the fabrication of screen printed electrodes (SPEs). In fact, SPE is an assembly of three electrodes, working, counter and reference electrodes, which are printed on chemically inert plastic or ceramic substrate. Screenprinted electrodes (SPE) have attracted considerable attention in recent years because they generally offer beneficial attributes over the traditional electrodes, such as economic substrate, diversity, low cost, and especially the possibility of mass production [15-17]. Unfortunately, the bare electrode usually suffer from a slow response and low reproducibility. This is probably due to relatively low electron-transfer rates obtained at the surface of such electrodes because of the low diffusion coefficient of the analytes in the electrode. Over the past few years, the design of electrochemical sensors has been developed to improve the analytical performance in terms of sensitivity, selectivity, reliability, ease of fabrication and use, as well as lower costs [18-21].

The unique electronic properties of nanomaterials have been widely exploited in electrochemistry as a means of promoting the electron transfer reaction for a wide range of electrochemical sensors applications [22-27]. Zinc oxide ( $\mathrm{ZnO}$ ) is one of the most important and versatile multifunctional nanomaterial in metal oxide family. It is used for various hightechnological applications due to its inherent properties, to name a few, optical band gap energy (3.37 ev), high- exciton binding energy (60 meV), biocompatibility, highelectron communication features, etc. Due to excellent properties, recently, ZnOnanomaterials are used as efficient photocatalysts for the photocatalytic degradation of harmful and toxic organic dyes, and also as potential electron mediators for the fabrication of highly sensitive chemical sensors. However, electron transfer in $\mathrm{ZnO}$ is slow because of its semiconducting characteristics. Thus, various metal nanoparticles possessing high conductivity have been incorporated in $\mathrm{ZnO}$ to improve its performance. Silver, which is the most highly conducting material, has been doped in $\mathrm{ZnO}$ to prepare Ag-ZnOnanocomposites, showing enhanced photocatalytic performance [28].

This work seems to develop a novel electrochemical sensor using a screen printed electrode modified by Ag-ZnOnanocomposite for the sensitive and selective determination of acetylcholine and epinephrine. Because of the excellent electrochemical performance of Ag-ZnO/SPE, enhanced voltammetric response to acetylcholine and epinephrine was observed on the modified electrode. Based on such a modified electrode, a highperformance electrochemical sensor for the simultaneous determination of epinephrine and acetylcholine in real sample was demonstrated. 


\section{Apparatus and chemicals}

An Autolabpotentiostat/galvanostat (PGSTAT $302 \mathrm{~N}$, Eco Chemie, the Netherlands) was applied for measuring electrochemicals. General Purpose Electrochemical System (GPES) software was employed to control conditions of experiments. The screenprinted electrode (DropSens, DRP-110, Spain) includes 3 main sections that contain a silver pseudo-reference electrode, a graphite working electrode, and graphite counter electrode. $\mathrm{pH}$ was measured by a Metrohm $710 \mathrm{pH}$ meter.

Epinephrine, acetylcholine, and all the remaining reagents had an analytical grade. They have been prepared via Merck (Darmstadt, Germany). Orthophosphoric acid and the related salts that were above the $\mathrm{pH}$ range of 2.0-9.0 were used for preparing the buffer solutions.

\section{Synthesis of $\mathrm{Ag}-\mathrm{ZnO}$ nanoplates}

Formation of composite of Ag-ZnO nanoplates were started by the preparation of $100 \mathrm{~mL}$ of solution included $\mathrm{ZnCl}_{2}(0.05 \mathrm{M})$ and $\mathrm{AgNO}_{3}$ (0.0169 g) at $\mathrm{pH}=13$. The solution was kept at $90^{\circ} \mathrm{C}$ for $1 \mathrm{~h}$. The pH of solution was adjusted by $\mathrm{NaOH}$ solution (1 M). Synthesis process was completed by increasing temperature to $98^{\circ} \mathrm{C}$ for $3 \mathrm{~h}$. After preparation and precipitation of Ag-ZnOnano plates, the precipitate was centrifuged at $15,000 \mathrm{rpm}$ for $20 \mathrm{~min}$. Separated precipitate was washed by methanol and water three times, respectively. Finally, it was dried in 70 ${ }^{\circ} \mathrm{C}$ for $2 \mathrm{~h}$. Typical SEM of Ag-ZnO nanoplates is shown in Figure 1.

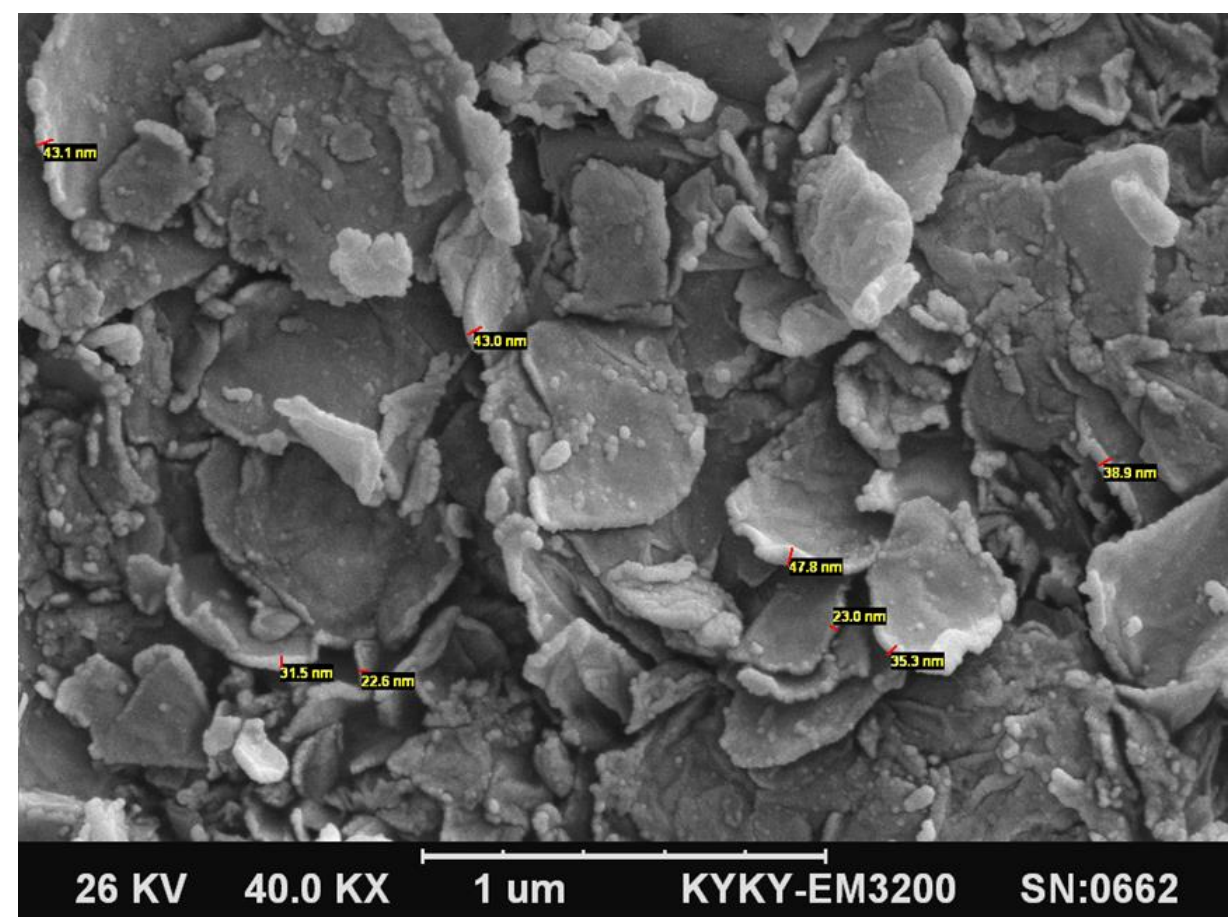

FIGURE 1 SEM image of Ag-ZnO nanoplates

\section{Preparing electrode}

Ag-ZnO nanoplates have been used to coat the bare screen-printed electrode. A stock solution of $\mathrm{Ag}-\mathrm{ZnO}$ nanoplates in $1 \mathrm{~mL}$ of aqueous solution has been prepared by distributing $1 \mathrm{mg}$ of Ag-ZnO nanoplates via ultra-sonication for 30 minutes, whereas $5 \mu \mathrm{l}$ of aliquots of the Ag-ZnO suspension solution has been cast on carbon working electrodes. Then, we waited for the solvent evaporation at room temperature. 


\section{Preparing real samples}

Urine samples have been kept in a refrigerator directly after gathering. Ten $\mathrm{mL}$ of samples have been centrifuged for fifteen minutes at 2,000 rpm. The supernatant has been filtered by a $0.45 \mu \mathrm{m}$ filter. Next, various volumes of solution has been transported into a $25 \mathrm{~mL}$ volumetric flask and diluted to the mark with PBS $(\mathrm{pH}=7.0)$. This diluted urine samples were anaesthetized with different amounts of epinephrine and acetylcholine. The content of epinephrine and acetylcholine have been analysed by the suggested procedure by employing the standard addition method.

The epinephrine and acetylcholine injections were diluted 10 times with water; then, different volumes of the diluted solutions were transferred into a $10 \mathrm{~mL}$ volumetric flask and diluted to the mark with PBS (pH 7.0). The diluted sample was spiked with different amounts of epinephrine and acetylcholine.

\section{Result and discussion}

Electrochemical properties of epinephrine on Ag-ZnO/SPE surface

The electrochemical behaviour of epinephrine is dependent on the $\mathrm{pH}$ value of the aqueous solution [Figure2]. Therefore, $\mathrm{pH}$ optimization of the solution seems to be necessary in order to obtain the electrocatalytic oxidation of epinephrine. Thus, the electrochemical behaviour of epinephrine was studied in 0.1 M PBS in different $\mathrm{pH}$ values $(2.0<\mathrm{pH}<9.0)$ at the surface of Ag-ZnO/SPE by CV. It was found that the electrocatalytic oxidation of epinephrine at the surface of Ag-ZnO/SPE was more favoured under neutral conditions than in acidic or basic medium, because the obtained current was more than other pHs. Thus, the pH 7.0 was chosen as the optimum $\mathrm{pH}$ for electrocatalysis of epinephrine oxidation at the surface of $\mathrm{Ag}-\mathrm{ZnO} / \mathrm{SPE}$ (Figure 2).

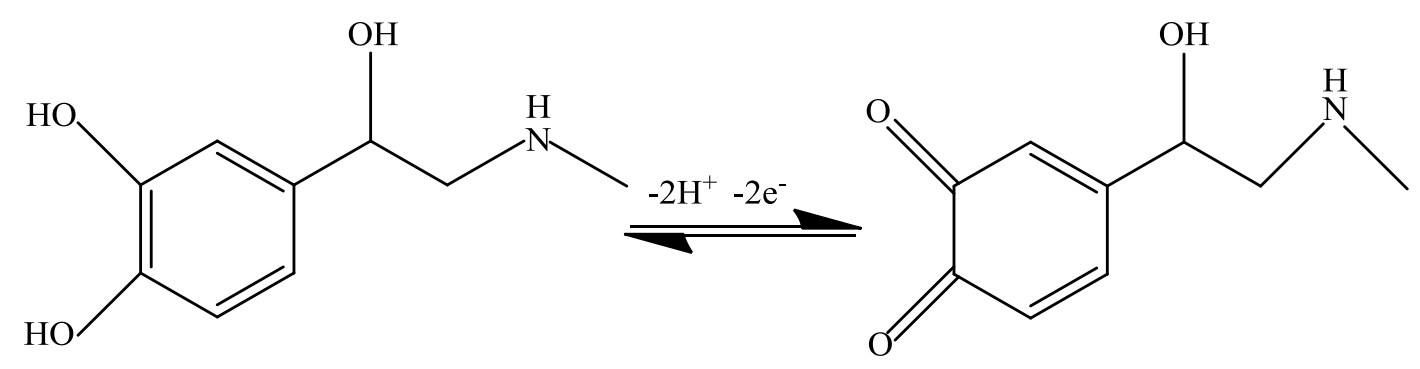

FIGURE 2 Electrochemical oxidation of epinephrine

Figure 3 shows responses of $\mathrm{CV}$ to electro-oxidation of $125.0 \mu$ Mepinephrine at the unmodified SPE (curve b) and Ag$\mathrm{ZnO/SPE}$ (curve a). The peak potential occurs at $200 \mathrm{mV}$ due to epinephrine oxidation, which is around $120 \mathrm{mV}$ more negative than the unchanged SPE. Furthermore, Ag-
ZnO/SPE exhibits very high anodic peak currents for epinephrine oxidation than that of the unchanged SPE. This showed a significant improvement of the electrode performance toward epinephrine oxidation by changing the constant SPE with Ag-ZnO. 


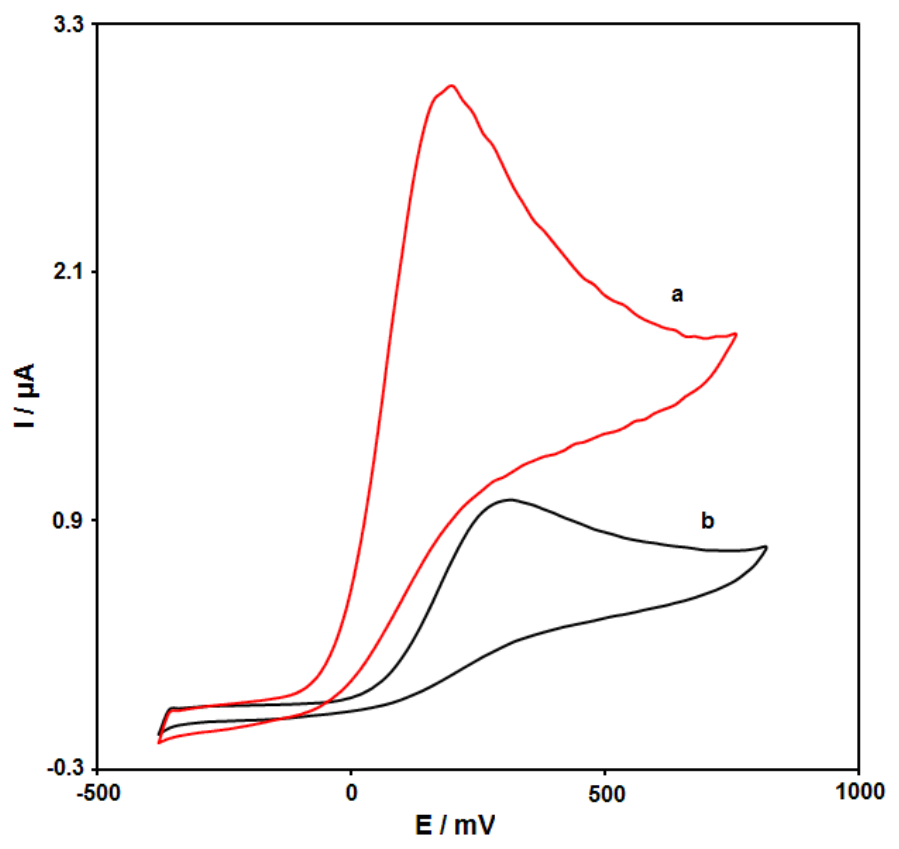

FIGURE $3 \mathrm{CVs}$ of a) Ag-ZnO/SPE and b) unmodified SPE in the presence of $125.0 \mu \mathrm{M}$ of epinephrine at $\mathrm{pH}$ 7.0. In all cases, the scan rate was $50 \mathrm{mV} \mathrm{s}^{-1}$

\section{Effect of scan rate on the results}

Researchers investigated the impact of the rates of potential scan on epinephrine oxidation current (Figure 4). Findings indicated induction of enhancement in the current of the peak by the increased potential scan rate. Additionally, diffusion in oxidation processes are monitored, as inferred by the linear dependence of the anodic peak current (Ip) on the square root of the potential scan rate $\left(v^{1 / 2}\right)[29]$.

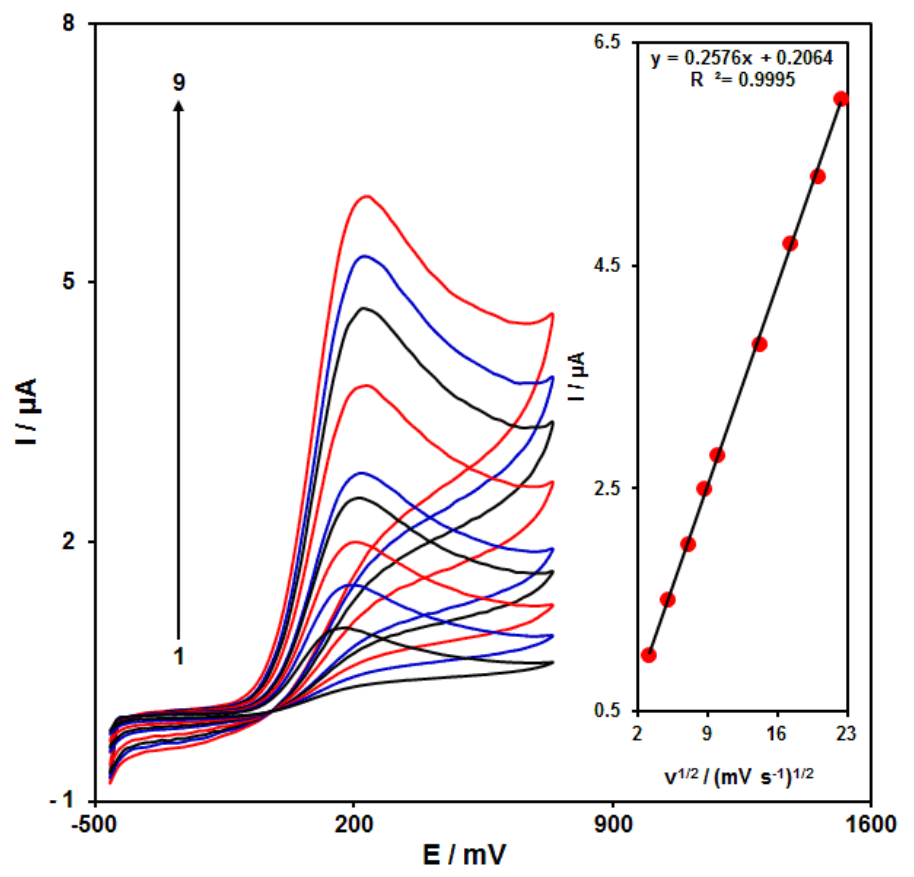

FIGURE 4 CVs of Ag-ZnO/SPE in $0.1 \mathrm{M}$ PBS (pH 7.0) containing $75.0 \mu \mathrm{M}$ of epinephrine at various scan rates; numbers 1-9 correspond to $10,25,50,75,100,200,300,400$ and 500 $\mathrm{mV} \mathrm{s}^{-1}$, respectively. Inset: Variation of anodic peak current vs. square root of scan rate. 


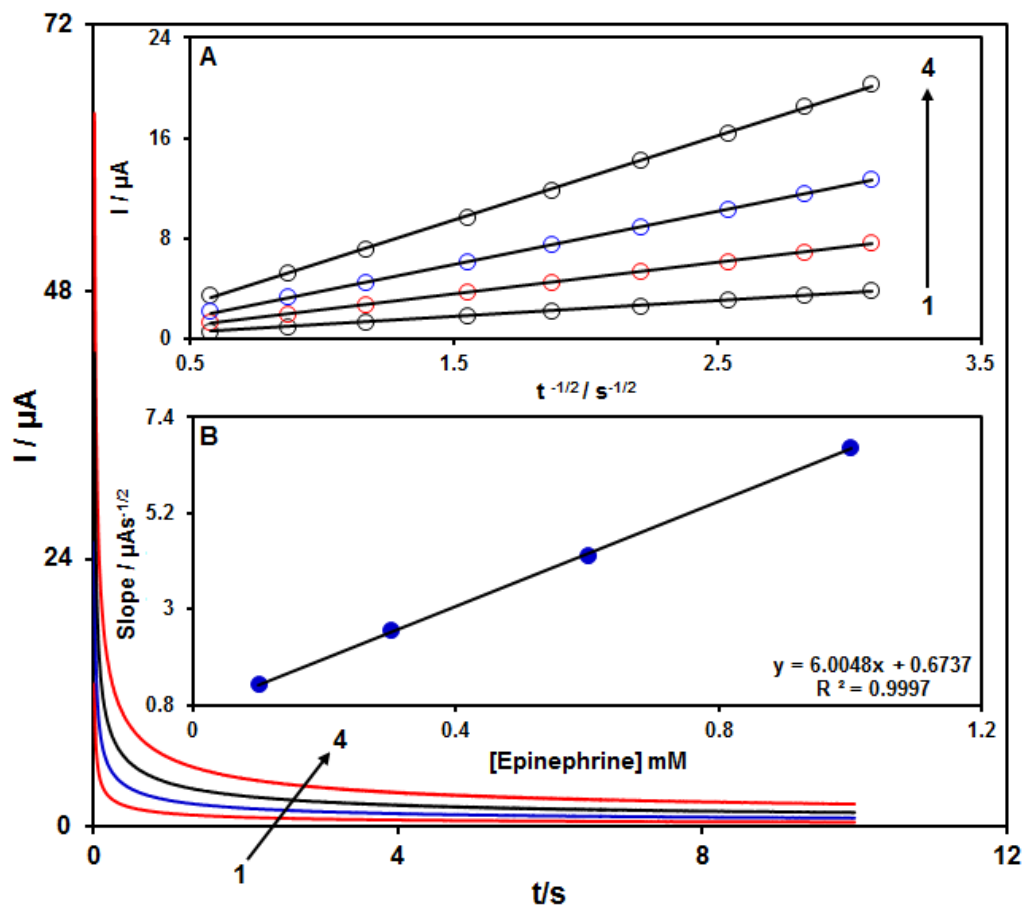

FIGURE 5 Chronoamperograms obtained at Ag-Zn0/SPE in $0.1 \mathrm{M}$ PBS (pH 7.0) for different concentrations of epinephrine. The numbers 1-4 correspond to $0.1,0.3,0.6$ and $1.0 \mathrm{mM}$ of epinephrine. Insets: (a) Plots of I vs. $t^{-1 / 2}$ obtained from chronoamperograms 1-4. (b) Plot of the slope of the straight lines against epinephrine concentrations.

\section{Chronoamperometric analyse}

Chronoamperometric measurements of epinephrine at Ag-ZnO/SPE were conducted by adjusting the working electrode potential at $0.25 \mathrm{~V}$ for different concentrations of epinephrine (Figure 5) in PBS (pH 7.0). For electroactive materials (epinephrine in this case) with a diffusion coefficient of $\mathrm{D}$, the Cottrell equation describes current seen for electrochemical reaction at the mass transport limited condition [29]:

$$
\mathrm{I}=\mathrm{nFAD}{ }^{1 / 2} \mathrm{C}_{\mathrm{b}} \pi^{-1 / 2} \mathrm{t}^{-1 / 2}
$$

where $\mathrm{D}$ and $\mathrm{C}_{\mathrm{b}}$, respectively, represent diffusion coefficient $\left(\mathrm{cm}^{2} \mathrm{~s}^{-1}\right)$ and bulk concentration $\left(\mathrm{mol} \mathrm{cm}^{-3}\right)$. Experimental plots of I versus $t^{-1 / 2}$ were used with the best fits for various concentrations of epinephrine (Figure 5A). Then, the resultant straight lines slopes were drawn against epinephrine concentrations (Figure 5B). According to the resultant slope and the Cottrell equation, mean values of $D$ were $3.1 \times 10^{-6} \mathrm{~cm}^{2} / \mathrm{s}$ for
epinephrine.This value is comparable with some previous reports $\left(1.04 \times 10^{-6} \mathrm{~cm}^{2} / \mathrm{s}\right.$ [32]).

\section{Calibration curve and LOD}

The electro-oxidation peak currents of epinephrine at Ag-ZnO/SPE surface can be applied to define epinephrine in the solution. Since the increased sensitivity and more suitable properties for analytical utilizations are considered as the benefits of differential pulse voltammetry (DPV), Ag-ZnO/SPE in 0.1 M PBS consisting of different distinct concentrations of epinephrine was used to conduct DPV experiments (Figure 6) (Initial potential $=-100 \mathrm{mV}$, End potential $=425 \mathrm{mV}$, Step potential $=0.01 \quad \mathrm{~V}$ and pulse amplitude $=0.025 \mathrm{~V}$ ). It was found that the electrocatalytic peak currents of epinephrine oxidation at $\mathrm{Ag}-\mathrm{ZnO} / \mathrm{SPE}$ surface linearly depended on epinephrine concentrations above the range of $0.13-435.0 \mu \mathrm{M}$ (with a correlation coefficient of 0.9994), while determination limit $(3 \sigma)$ was achieved to be 
$0.04 \mu \mathrm{M}$. These values are comparable with

(Table 1).

the values obtained by other researchers

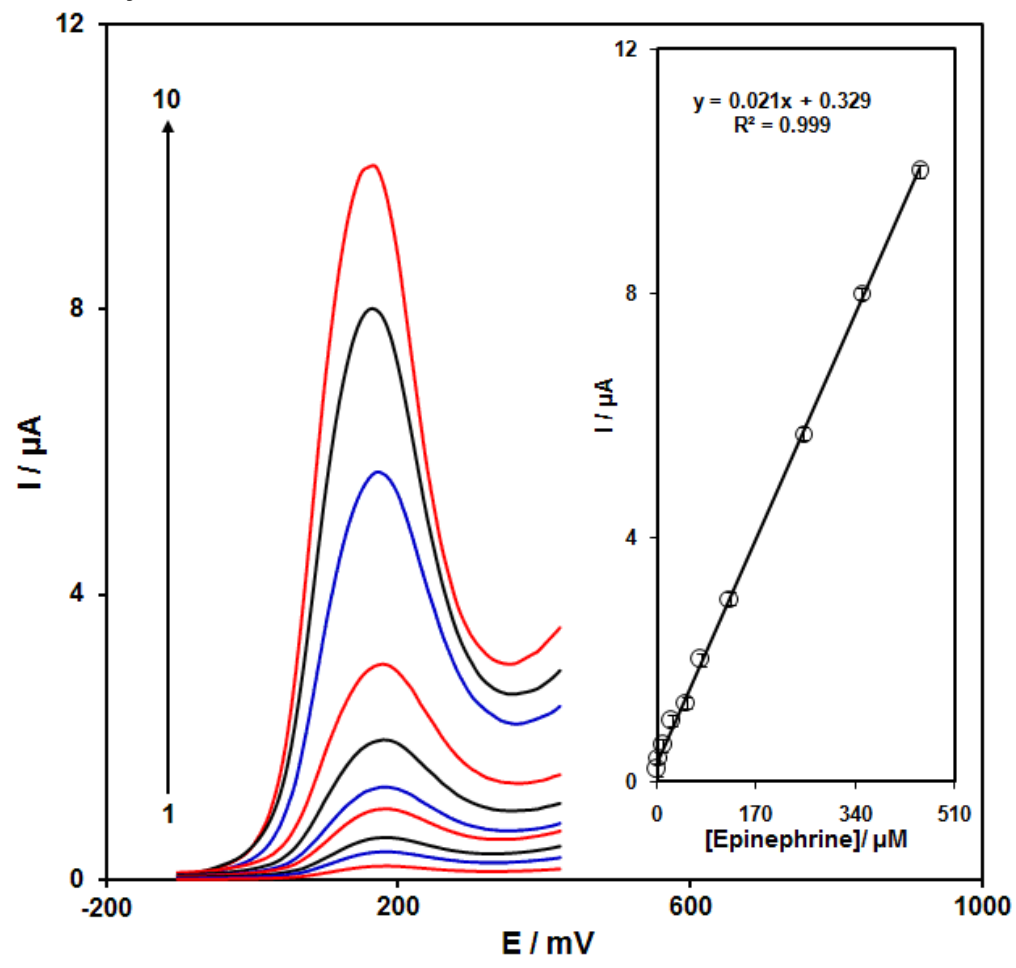

FIGURE 6 DPVs of Ag-ZnO/SPEin 0.1 M PBS (pH 7.0) containing different concentrations of epinephrine. Numbers 1-10 correspond to, $0.13,2.0,10.0,25.0,50.0,75.0,125.0,250.0,350.0$ and $450.0 \mu \mathrm{M}$ of epinephrine. The inset shows the plot of the peak current as a function of the epinephrine concentration in the range of $0.13-450.0 \mu \mathrm{M}$.

TABLE 1 Comparison of the efficiency of some modified electrodes used in detection of epinephrine

\begin{tabular}{|c|c|c|c|c|c|}
\hline Method & Electrode & Modifier & $\begin{array}{l}\text { Linear } \\
\text { range }(\mu \\
\text { mol/L) }\end{array}$ & $\begin{array}{c}\text { Detection } \\
\text { limit }(\mu \\
\text { mol/L) }\end{array}$ & Ref \\
\hline Voltammetry & Carbon paste & $\begin{array}{c}\mathrm{BBNBH} / \mathrm{TiO} 2 \\
\text { nanoparticle }\end{array}$ & $1.0-600.0$ & 0.2 & 30 \\
\hline Voltammetry & Screen printed & $\begin{array}{c}\text { o-SWCNHs } \\
\text { 2-(2.3-Dihydroxv }\end{array}$ & $2.0-2500.0$ & 0.1 & 31 \\
\hline Voltammetry & Gold & $\begin{array}{l}\text { phenyl)- } \\
\text { 1,3-dithiane }\end{array}$ & $0.7-500.0$ & 0.51 & 32 \\
\hline Voltammetry & Glassy carbon & Zn-Al LDH film & $0.50-300.0$ & 0.13 & 33 \\
\hline Voltammetry & Glassy carbon & PMaIG/MWCNT & $0.1-100.0$ & 0.08 & 34 \\
\hline Voltammetry & Screen printed & Ag-ZnO & $0.13-450.0$ & 0.04 & $\begin{array}{l}\text { This } \\
\text { work }\end{array}$ \\
\hline
\end{tabular}

\section{Simultaneous determination epinephrine and acetylcholine}

We have not seen any report about using an SPE modified with Ag-ZnO for determining epinephrine and acetylcholine. Moreover, due to reality that electrochemical detection of epinephrine in the front of acetylcholine with the help of un-modified electrodes has the caveat of interventions by acetylcholinebecause of relative adjacent oxidation capacities of the two specimens, it can be regarded as a crucial phase. Such a phase has been conducted by simultaneous 
alterations of analytes concentrations and achieving DPVs (Figure 7) (Initial potential=$240 \mathrm{mV}$, End potential $=900 \mathrm{mV}$, Step potential $=0.01 \mathrm{~V}$ and pulse amplitude $=0.025$ V). Findings reported certain anodic at 180 and $740 \mathrm{mV}$ for epinephrine and acetylcholine oxidation, proving using the Ag$\mathrm{ZnO/SPE}$; these two analytes can be detected without severe interventions from each another

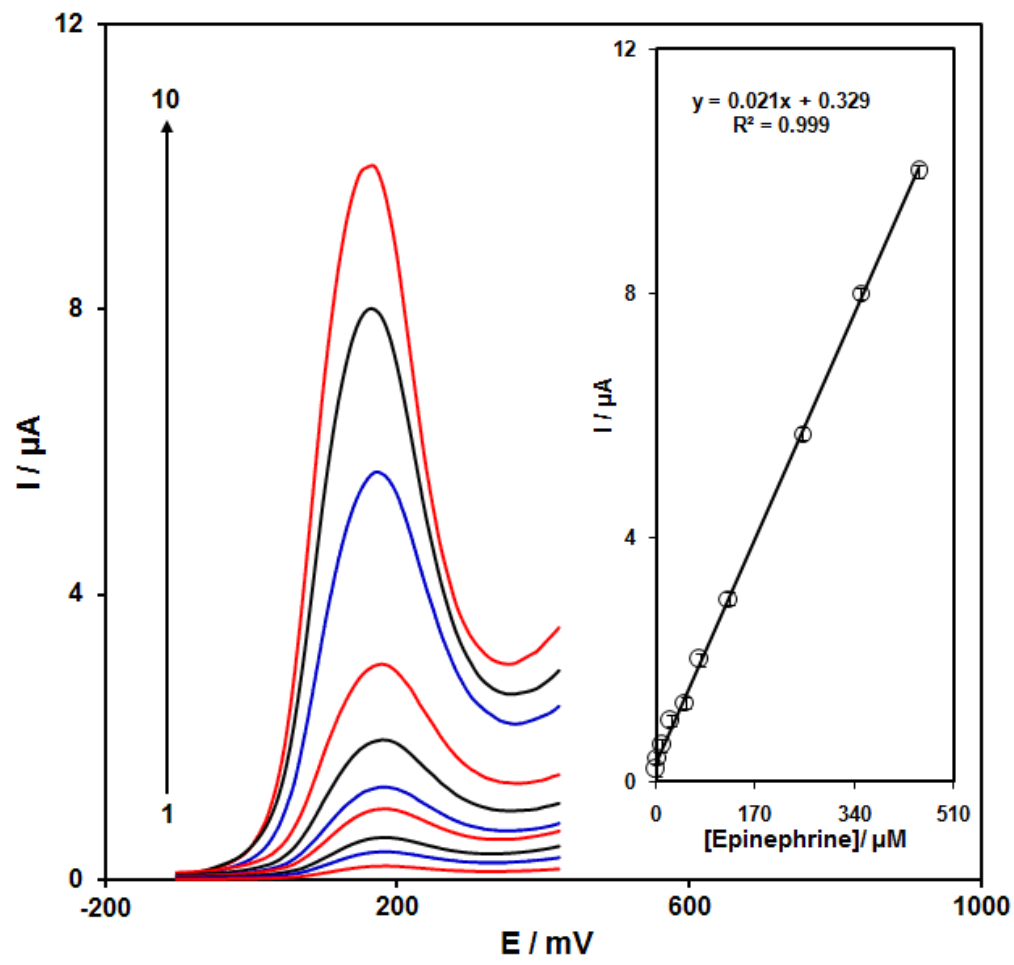

FIGURE 7 DPVs achieved at Ag-ZnO/SPE surface in 0.1 M PBS (pH 7.0) consisting of various concentrations of epinephrine and acetylcholine. DPVs from internal to external respectively is corresponding to $2.0+5.0,10.0+10.0,25.0+25.0,50.0+50.0,100.0+100.0,200.0+225.0$ and $400.0+500.0 \mu \mathrm{M}$ of epinephrine and acetylcholine. Insets: (a) plot of Ip versus epinephrine concentration and (B) plot of Ip versus acetylcholine concentration.

The repeatability and stability of AgZnO/SPE

To study the long-term stability of the Ag$\mathrm{ZnO/SPE}$, its performance was assessed over a 2-weeks period. For this purpose, the experiments were repeated after the modified electrode had been stored at room temperature for two weeks. As cyclic voltammograms demonstrated, no tangible change was observed in the peak potential of epinephrine oxidation except for a drop less than $2.6 \%$ compared with initial response. The antifouling capacity of the modified electrode towards oxidation of epinephrine and its corresponding oxidation products were investigated by $\mathrm{CV}$ analysis.
Voltammograms were recorded in the presence of epinephrine after cycling the potential 12 times at a scan rate of $50 \mathrm{mV} \mathrm{s}^{-1}$. According to the results, the peak potentials remained unchanged except a decrement less than $2.2 \%$. These results confirmed that the modified Ag-ZnO/SPE offers higher sensitivity and reduced fouling effect towards epinephrine and its oxidation products.

\section{Analysis of real samples}

To assess the applicability of the application of the modified electrode for the determination of epinephrine and acetylcholine in real samples, the described method was applied to the determination of 
epinephrine and acetylcholine in epinephrine and acetylcholine injections, and urine samples. Therefore, the standard addition technique was applied. Table 2 reports the results. Acceptable recoveries of epinephrine and acetylcholine were observed, and reproducible results were shown with regard to the mean relative standard deviation (R.S.D.).

TABLE 2 Determination of epinephrine and acetylcholine in real samples. All the concentrations are expressed in $\mu \mathrm{M}(\mathrm{n}=5)$.

\begin{tabular}{ccccccccc}
\hline \multicolumn{2}{c}{ R.S.D. (\%) } & \multicolumn{2}{c}{ Recovery (\%) } & \multicolumn{2}{c}{ Found } & \multicolumn{2}{c}{ Spiked } & Sample \\
\hline $\begin{array}{c}\text { Acetylch } \\
\text { oline }\end{array}$ & $\begin{array}{c}\text { Epinep } \\
\text { hrine }\end{array}$ & $\begin{array}{c}\text { Acetylcho } \\
\text { line }\end{array}$ & $\begin{array}{c}\text { Epinephrin } \\
\text { e }\end{array}$ & $\begin{array}{c}\text { Acetylchol } \\
\text { ine }\end{array}$ & $\begin{array}{c}\text { Epineph } \\
\text { rine }\end{array}$ & $\begin{array}{c}\text { Acetylch } \\
\text { oline }\end{array}$ & $\begin{array}{c}\text { Epinephri } \\
\text { ne }\end{array}$ \\
- & 3.4 & - & - & - & 5.5 & 0 & 0 & \\
3.2 & 2.7 & 102.0 & 98.6 & 5.1 & 6.9 & 5.0 & 2.5 & Epineph \\
1.8 & 2.4 & 97.0 & 101.9 & 9.7 & 10.7 & 10.0 & 5.0 & rine \\
2.6 & 1.9 & 99.3 & 103.1 & 14.9 & 13.4 & 15.0 & 7.5 & injection \\
2.3 & 2.8 & 101.5 & 99.3 & 20.3 & 15.4 & 20.0 & 10.0 & \\
2.8 & - & - & - & 3.0 & - & 0 & 0 & \\
2.0 & 1.9 & 98.2 & 102.7 & 5.4 & 7.7 & 2.5 & 7.5 & Acetylch \\
3.0 & 2.7 & 103.7 & 98.4 & 8.3 & 12.3 & 5.0 & 12.5 & oline \\
1.6 & 3.5 & 100.9 & 100.6 & 10.6 & 17.6 & 7.5 & 17.5 & injection \\
2.4 & 2.2 & 99.2 & 99.6 & 12.9 & 22.4 & 10.0 & 22.5 & \\
- & - & - & - & - & - & 0 & - & \\
3.0 & 2.6 & 102.0 & 98.0 & 5.1 & 4.9 & 5.0 & 5.0 & \\
2.2 & 2.8 & 97.0 & 102.7 & 9.7 & 7.7 & 10.0 & 7.5 & Urine \\
2.4 & 1.7 & 101.3 & 97.0 & 15.2 & 9.7 & 15.0 & 10.0 & \\
1.9 & 3.5 & 99.0 & 102.4 & 19.8 & 12.8 & 20.0 & 12.5 & \\
\hline
\end{tabular}

\section{Conclusion}

In summary, we have established a facile and sensitive electrochemical sensor based on Ag$\mathrm{ZnO}$ modified SPE. It is found that the Ag-ZnO has a high surface area and good conductivity benefiting electron transfer and shows excellent electrocatalytic activity toward oxidation of epinephrine and acetylcholine. A linear response obtained in the range of 0.13 to $450.00 \mu \mathrm{M}$ with detection limit of $0.04 \mu \mathrm{M}$ for epinephrine. Clearly separated oxidation peaks of epinephrine and acetylcholine were obtained, allowing for simultaneous determination of both analytes using $\mathrm{Ag}$ $\mathrm{ZnO/SPE.} \mathrm{Furthermore,} \mathrm{the} \mathrm{developed} \mathrm{sensor}$ showed good repeatability, reproducibility and stability.

\section{Acknowledgements}

The authors acknowledge the financial support provided for this project (Project No.
98000289 and ethics code EC/98-28/KNRC) by the Neuroscience Research Center, Kerman University of Medical Sciences, Kerman, Iran.

\section{Orcid:}

Somayeh Tajik: https://orcid.org/0000-00021151-5515

\section{References}

[1] C.H. Mak, C. Liao, Y. Fu, M. Zhang, C.Y. Tang, Y.H. Tsang, F. Yan, J. Mater. Chem. C, 2015, 3, 6532-6538.

[2] H. Beitollahi, Z. Dourandish, S. Tajik, M.R. Ganjali, P. Norouzi, F. Faridbod, J. Rare Earths, 2018, 36, 750-757.

[3] L.I. Tomé, C.M. Brett, Electroanalysis, 2019, 31, 704-710.

[4] P. Balasubramanian, T.S.T. Balamurugan, S.M. Chen, T.W. Chen, T. Sathesh, ACS Sustain. Chem. Eng, 2018, 7, 5669-5680.

[5] F.T. Moreira, M.G.F. Sale, M. Di Lorenzo, Biosens. Bioelectron, 2017, 87, 607-614. 
[6] H. Soltani, H. Beitollahi, A.H. HatefiMehrjardi, S. Tajik, M. Torkzadeh-Mahani, Anal. Bioanal. Electrochem, 2014, 6, 67-79.

[7] N.S. Anuar, W.J. Basirun, M. Ladan, M. Shalauddin, M.S. Mehmood, Sens. Actuators B Chem, 2018, 266, 375-383.

[8] S.E. Baghbamidi, H. Beitollahi, S. Tajik, R. Hosseinzadeh, Int. J. Electrochem. Sci., 2016, 11, 10874-10883.

[9] J.D. Keighron, J. Wigström, M.E. Kurczy, J. Bergman, Y. Wang, A.S. Cans, ACS chem. neurosci, 2015, 6, 181-188.

[10] A. Taherkhani, T. Jamali, H. Hadadzadeh, H. Karimi-Maleh, H. Beitollahi, M. Taghavi, F. Karimi, Ionics, 2014, 20, 421-429.

[11] S. Sharma, N. Singh, V. Tomar, R. Chandra, Biosens. Bioelectron, 2018, 107, 7693.

[12] Q. He, J. Liu, X. Liu, Y. Xia, G. Li, P. Deng, D. Chen, Molecules, 2018, 23, 2130--2144.

[13] M. Eldefrawy, E.G.A. Gomaa, S. Salem, F. Abdel Razik, Prog. Chem. Biochem. Res., 2018, 1,11-18.

[14] M.M. Motaghi, H. Beitollahi, S. Tajik, R. Hosseinzadeh, Int. J. Electrochem. Sci, 2016, 11, 7849-7860.

[15] A. Gevaerd, C.E. Banks, M.F. Bergamini, L.H. Marcolino-Junior, Electroanalysis, 2019, 31, 838-843.

[16] M.R. Ganjali, Z. Dourandish, H. Beitollahi, S. Tajik, L. Hajiaghababaei, B. Larijani, Int. J. Electrochem. Sci., 2018, 13, 2448-2461.

[17] N. Jeromiyas, E. Elaiyappillai, A.S. Kumar, S.T. Huang, V. Mani, J. Taiwan Inst Chem. Eng, 2019, 95, 466-474.

[18] S. Mohammadi, A. Taheri, Z. RezayatiZad, Prog. Chem. Biochem. Res., 2018, 1, 1-10.

[19] M. Mazloum-Ardakani, H. Beitollahi, M.K. Amini, F. Mirkhalaf, B.F. Mirjalili, A. Akbari, Analyst, 2011, 136, 1965-1970.

[20] M. Govindasamy, S.F. Wang, R. Jothiramalingam, S.N. Ibrahim, H.A. Allohedan, Microchim. Acta, 2019, 186, 420.

[21] H. Beitollahi, S. Tajik, M.H. Asadi, P. Biparva, J. Anal. Sci. Technol., 2014, 5, 29-37.
[22] G. Vinodhkumar, R. Ramya, M. Vimalan, I. Potheher, A. Cyrac,Peter. Prog. Chem. Biochem. Res., 2018, 1, 40-49.

[23] A. Dehno Khalaji, M. Ghorbani, M. Dusek, V. Eigner, Chem, Methodol, 2020, 4, 143-151.

[24] H.M. Moghaddam, H. Beitollahi, S. Tajik, S. Jahani, H. Khabazzadeh, R. Alizadeh, Russ. J. Electrochem., 2017, 53, 452-460.

[25] H.M. Moghaddam, H. Beitollahi, S. Tajik, M. Malakootian, H.K. Maleh, Environ. Monit. Assess., 2014, 186, 7431-7441.

[26] B.Y. Sahyar, M. Kaplan, M. Ozsoz, E. Celik, S. Otles, Bioelectrochemistry, 2019, 130, 07327-107348.

[27] J. Yoon, E. Lee, D. Lee, T.S. Oh, Y.S. Yoon, D.J. Kim, J. Electrochem. Soci., 2017, 164, B558-B560.

[28] H. Beitollahi, A. Gholami, M.R. Ganjali, Mater. Sci. Engin. C, 2016, 69, 128-133.

[29] A.J. Bard, L.R. Faulkner, 2nd ed. Wiley, New York, 2001.

[30] M. Mazloum-Ardakani, H. Beitollahi, M.A. Sheikh Mohseni, A. Benvidi, H. Naeimi, M. Nejati-Barzoki, N. Taghavinia, Colloids Surf B: Biointerfaces, 2010, 76, 82-87.

[31] F. Valentini, E. Ciambella, V. Conte, L. Sabatini, N. Ditaranto, F. Cataldo, M. Prato, Biosens. Bioelectron, 2014, 59, 94-98.

[32] M. Mazloum-Ardakani, H. Beitollahi, M.K. Amini, B.F. Mirjalili, F. Mirkhalaf, J. Electroanal. Chem., 2011, 651, 243-249.

[33] F. Ni, Y. Wang, D. Zhang, F. Gao, M. Li, Electroanalysis, 2010, 22, 1130-1135.

[34] J.B. Raoof, R. Ojani, M. Baghayeri, Turkish J. Chem., 2013, 37, 36-50.

How to cite this article: Mohammad Reza Aflatoonian*, Somayeh Tajik*, Behnaz Aflatoonian, Mehri-Saddat Ekrami-Kakhki, Reza Alizadeh. Simultaneous electrochemical determination of epinephrine and acetylcholine using modified screen printed electrode. Eurasian Chemical Communications, 2020, 2(5), 563572.

Link: http://www.echemcom.com/article_99097. html 